\title{
Design, Synthesis and Properties of D-A-D' Asymmetric Structured Electrochromic Polymers Based on Fluorenone as Acceptor Units
}

Junlei Liu, Lin Li, Ruoteng Xu, Kaili Zhang, Mi Ouyang*, Weijun Li, Xiaojing Lv, Cheng Zhang*

State Key Laboratory Breeding Base for Green Chemistry Synthesis Technology, College of Chemical Engineering, Zhejiang University of Technology, Hangzhou, 310014, P. R. China.

Corresponding Author

*E-mail: ouyang@zjut.edu.cn. Tel: +86-571-88320508 (M.O.).

*E-mail: czhang@zjut.edu.cn. Tel: +86-571-88320508 (C.Z.). 


\section{Experimental}

The catalyst (beta-4)-platinum and bis(triphenylphosphine)-palladium(II) chloride were purchased from EnergyChemical, the rest of chemicals were purchased from Aladdin and used without further purification in this study. The monomer 2, 3 and 5 was synthesized by the Suzuki coupling reaction, the monomer 4 was synthesized by the Still coupling reaction, and the synthetic routes are shown in Scheme S1.

Scheme S1. Chemical Structures and Synthetic Route of SWS, SWE and SWT.

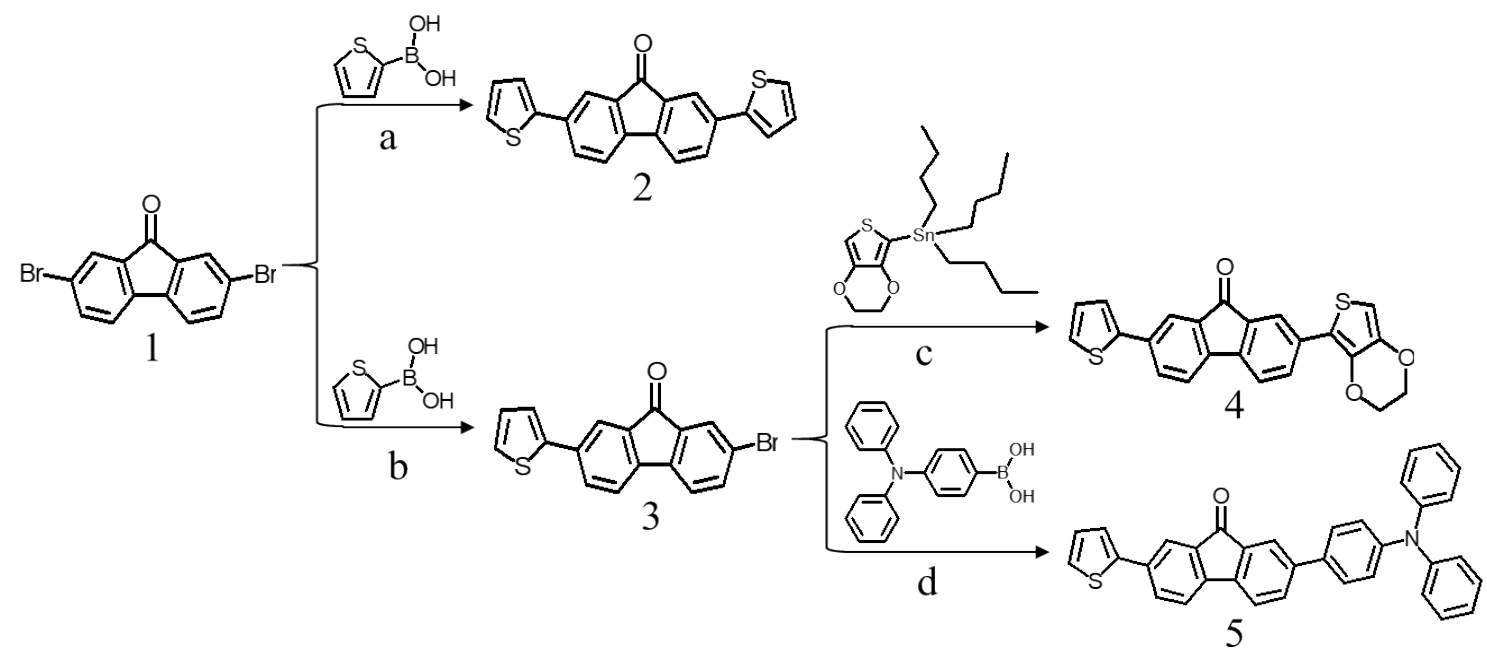

Synthetic conditions: $a, \quad b$ and $d$ containing $P d\left(\mathrm{PPh}_{3}\right)_{4}(0.025 \mathrm{mmol})$ and $\mathrm{K}_{2} \mathrm{CO}_{3}(3 \mathrm{mmol}) \quad$ in $\quad \mathrm{THF}(30 \mathrm{ml}) /$ Toluene $(20 \mathrm{ml}) / \mathrm{H}_{2} \mathrm{O}(2 \mathrm{ml}) ; \quad$ c containing $\mathrm{Pd}\left(\mathrm{PPh}_{3}\right)_{2} \mathrm{Cl}_{2}(0.025 \mathrm{mmol})$ and $\mathrm{K}_{2} \mathrm{CO}_{3}(3 \mathrm{mmol})$ in $\mathrm{THF}(30 \mathrm{ml}) /$ Toluene $(20 \mathrm{ml})$. Monomer 1 is 2,7-Dibromo-fluoren-9-one. Monomer 2 is 2,7-Di-thiophen-2-yl-fluoren-9-one(SWS). Monomer 3 is 2-Bromo-7-thiophen-2-yl-flu-oren-9-one. $\quad$ Monomer 4 is 2-(2,3-Dihydro-thieno[3,4-b][1,4]dioxin-5-yl)-7-thiophen-2-yl-fluoren-9-one(SWE).

Monomer 5 is 2-(4-Diphenylamino-phenyl)-7-thiophen-2-yl-fluoren-9-one(SWT). 
All the target products were separated and purificated by column chromatography, and analysed using the 1HNMR spectroscopy [Bruker SpectrospinAvance ANANCE III (500 MHz)]. Mass spectrometry (MS) studies were done with a GCT Premier spectrometer(Waters, USA). The thickness of polymeric films were controlled by Dektak-XT 10th (BRUKER, Germany). The micro-FTIR spectra of monomers and their polymeric film samples in the neutral states were examined by a Nicolet 6700 Fourier-transform infrared spectrometer (FTIR) (Thermo Fisher Nicolet, USA). The images of electrochromic films were taken using Canon EOS 60D (Canon, Japan). All of the electrochemical studies were performed on a CHI660E electrochemical work station (CHI, Chenhua,Shanghai, China), with a three-electrode system containing a working electrode (ITO or ITO coated with the film), a counter electrode(platinum wire) and a reference electrode $(\mathrm{Ag} / \mathrm{AgCl}$, silver wire coated with $\mathrm{AgCl}$ in saturated $\mathrm{KCl}$ solution). An UV-1800 UV-vis spectrophotometer (Shimadzu, Japan) was used to spectroelectrochemical studies.

\section{Synthesis of 2,7-Di-thiophen-2-yl-fluoren-9-one(SWS)}

$3 \mathrm{mM}$ of 2,7-dibromo-9-fluorenone, $7 \mathrm{mM}$ of 2-thiopheneboronic acid and 3mM of potassium carbonate were dissolved in a mixed solvent of tetrahydrofuran $(20 \mathrm{ml}) /$ toluene $(30 \mathrm{ml})$, and $0.025 \mathrm{mM}$ (beta-4)-platinum and $2 \mathrm{ml}$ deionised water were added. The mixture was stirred under nitrogen atmosphere under reflux for $24 \mathrm{~h}$. The final solution was washed with deionised water and extracted with dichloromethane after the system cooled. The organic phase was dried 
by adding anhydrous magnesium sulfate, and the dichloromethane was removed under vacuum distillation. Then the product was purified by the silica gel column chromatography(petroleum ether- $\mathrm{CH}_{2} \mathrm{Cl}_{2} 1: 2$ as eluent) to obtain the final product as a orange solid in a $86 \%$ yield. $1 \mathrm{HNMR}\left(500 \mathrm{MHz}, \mathrm{CDCl}_{3}\right) \delta 7.95(\mathrm{~d}, \mathrm{~J}=1.4 \mathrm{~Hz}, 1 \mathrm{H})$, $7.76(\mathrm{dd}, \mathrm{J}=7.8,1.7 \mathrm{~Hz}, 1 \mathrm{H}), 7.55(\mathrm{~d}, \mathrm{~J}=7.8 \mathrm{~Hz}, 1 \mathrm{H}), 7.41(\mathrm{~d}, \mathrm{~J}=3.5 \mathrm{~Hz}, 1 \mathrm{H}), 7.35$ $(\mathrm{d}, \mathrm{J}=5.0 \mathrm{~Hz}, 1 \mathrm{H}), 7.13(\mathrm{dd}, \mathrm{J}=4.9,3.7 \mathrm{~Hz}, 1 \mathrm{H}) . \mathrm{MS}: \mathrm{m} / \mathrm{z}(\mathrm{EI}) 345.2(\mathrm{M}+$ ).

\section{Synthesis of 2-(2,3-Dihydro-thieno[3,4-b][1,4]dioxin-5-yl)-7-thiophen-2-yl \\ -fluoren-9-one (SWE)}

$2 \mathrm{mM}$ of 2,7-dibromo-9-fluorenone, $1 \mathrm{mM}$ of 2-thiopheneboronic acid and $2 \mathrm{mM}$ of potassium carbonate were dissolved in a mixed solution with tetrahydrofuran $(20 \mathrm{ml}) /$ toluene $(30 \mathrm{ml}), \quad 0.025 \mathrm{mM}$ (beta-4)-platinum and $2 \mathrm{ml}$ of deionised water were added. The mixture was stirred undernitrogen atmosphere at refluxtemperature for $12 \mathrm{~h}$. It was then extracted with deionised water and dichloromethane after the system cooled. The organic phase was dried by anhydrous magnesium sulfate, and the dichloromethane was removed under vacuum distillation. Then the product was purified by the silica gel column chromatography(petroleum ether- $\mathrm{CH} 2 \mathrm{Cl} 2$ 1:2 as eluent) to obtain the final product 2-bromo-7-thiophen-2-yl-fluoren-9-one (monomer 3) in a 88\% yield.

Besides, We need to get the (2,3-Dihydro-thieno[3,4-b][1,4]dio-xin-5-yl)-triethyl -stannane. 3,4-Ethylenedioxythiophene (EDOT, 14mmol, 2g) dissolved in the steamed tetrahydrofuran solvents $(80 \mathrm{ml})$, then $1.6 \mathrm{M} \mathrm{n}$-butyl lithium was added to the mixture slowly was stirred in nitrogen atmosphere under $-78^{\circ} \mathrm{C}$, then tributyltin 
chloride (18.8mmol, $6.12 \mathrm{~g}$ ) was added to the mixture slowly was stirred in nitrogen atmosphere after the temperature rise to $-40^{\circ} \mathrm{C}$, then the solution was warmed to room temperature and stirred for $8 \mathrm{~h}$.

Finally, $\quad 3 \mathrm{mM} \quad$ 2-Bromo-7-thiophen-2-yl-fluoren-9-one, $\quad 3 \mathrm{mM}$ (2,3-Dihydro-thieno[3,4-b][1,4]dioxin-5-yl)-triethyl-stannane and 2mM Potassium carbonate dissolved in the mixed solution of steamed tetrahydrofuran $(20 \mathrm{ml}) /$ toluene $(30 \mathrm{ml})$, and $0.025 \mathrm{mM} \mathrm{Pd}\left(\mathrm{PPh}_{3}\right)_{2} \mathrm{Cl}_{2}$ were added to the solution, then the reaction under reflux condition at nitrogen atmosphere for $36 \mathrm{~h}$. The final solution was extracted with the mixed reagent between deionised water and dichloromethane after the system cooling, dried the organic phase by adding magnesium sulfate anhydrous, and dichloromethane was removed under vacuum distillation. Then the product was purified by the silica gel column chromatography(petroleum ether- $\mathrm{CH}_{2} \mathrm{Cl}_{2}$ 1:1 as eluent) to obtain the final product as a red powder in a $63 \%$ yield. $1 \mathrm{H} \mathrm{NMR}\left(500 \mathrm{MHz}, \mathrm{CDCl}_{3}\right) \delta: 8.08(\mathrm{~d}, \mathrm{~J}=1.4 \mathrm{~Hz}, 1 \mathrm{H})$, $7.92(\mathrm{~d}, \mathrm{~J}=1.5 \mathrm{~Hz}, 1 \mathrm{H}), 7.82(\mathrm{dd}, \mathrm{J}=7.9,1.7 \mathrm{~Hz}, 1 \mathrm{H}), 7.73(\mathrm{dd}, \mathrm{J}=7.8,1.8 \mathrm{~Hz}, 1 \mathrm{H})$, $7.50(\mathrm{dd}, \mathrm{J}=7.6,4.0 \mathrm{~Hz}, 2 \mathrm{H}), 7.39(\mathrm{dd}, \mathrm{J}=3.6,1.0 \mathrm{~Hz}, 1 \mathrm{H}), 7.32(\mathrm{dd}, \mathrm{J}=5.1,1.0 \mathrm{~Hz}$, $1 \mathrm{H}), 7.11(\mathrm{dd}, \mathrm{J}=5.1,3.6 \mathrm{~Hz}, 1 \mathrm{H}), 6.35(\mathrm{~s}, 1 \mathrm{H}), 4.39-4.32(\mathrm{~m}, 2 \mathrm{H}), 4.30-4.23(\mathrm{~m}$, 2H).MS: m/z (EI) 403.2(M+).

\section{Synthesis of 2- (4-Diphenylamino-phenyl) -7-thiophen-2-yl-fluoren-9-one(SWT)}

$3 \mathrm{mM}$ of 4 -(diphenylamino)phenylboronic acid and $2 \mathrm{mM}$ of potassium carbonate were dissolved in the mixed solventoftetrahydrofuran $(20 \mathrm{ml}) /$ toluene( $30 \mathrm{ml}), 0.025 \mathrm{mM}$ (beta-4)-platinum and $2 \mathrm{ml}$ deionised water were added. The mixture was stirred under 
nitrogen atmosphere at reflux temperature for $8 \mathrm{~h}$. The solution was extracted by washing with deionised water and extraching with dichloromethane. The organic phasewas dried by adding anhydrousmagnesium sulfate, and dichloromethane was removed under reduced pressure. The product was purified by the silica gel column chromatography(petroleum ether- $\mathrm{CH}_{2} \mathrm{Cl}_{2} 1: 1$ as eluent) to obtain the final product as a dark-red powder in a 58\% yield. $1 \mathrm{H}$ NMR (500 MHz, DMSO) $\delta: 7.95-7.91(\mathrm{~m}, 1 \mathrm{H})$, $7.88(\mathrm{dd}, \mathrm{J}=10.1,5.0 \mathrm{~Hz}, 2 \mathrm{H}), 7.75-7.70(\mathrm{~m}, 1 \mathrm{H}), 7.63(\mathrm{dd}, \mathrm{J}=5.1,1.1 \mathrm{~Hz}, 1 \mathrm{H}), 7.36$ $(\mathrm{dd}, \mathrm{J}=8.4,7.5 \mathrm{~Hz}, 2 \mathrm{H}), 7.19(\mathrm{dd}, \mathrm{J}=5.1,3.6 \mathrm{~Hz}, 1 \mathrm{H}), 7.14-7.07(\mathrm{~m}, 3 \mathrm{H}), 7.05(\mathrm{~d}, \mathrm{~J}=$ 8.7 Hz, 1H). MS: m/z (EI) $506.1(\mathrm{M}+)$.

\section{Electrochemical polymerization of monomers}

The redox behavior of $1 \mathrm{mM}$ SWS, SWE and SWT were investigated via cyclic voltammetry $(\mathrm{CV})$ in $0.1 \mathrm{M}$ TBAP/dichloromethane/acetonitrile $\left(\mathrm{CH}_{2} \mathrm{Cl}_{2} / \mathrm{ACN}, 3 / 2\right.$, v/v)electrolyte solutions respectively. The electrochemical polymerization was recorded in a three-electrode cell, including ITO(CSG holding Co.LTD, Rs $\leq 10 \Omega \mathrm{cm}^{-2}$, the active area: $0.9 \mathrm{~cm} \times 4 \mathrm{~cm}$ ) as the working electrode which was washed for $15 \mathrm{~min}$ with $0.1 \% \mathrm{NaOH}$ (deionised water), ethanol, acetone, toluene, ethanol and acetone in sequence under ultrasound before using, platinum wire as the counter electrode, $\mathrm{Ag} / \mathrm{AgCl}$ as the reference electrode. The polymeric thin films of SWS, SWE and SWT were prepared by anodic oxidation polymerization at the applied voltage ranges of $0 \mathrm{~V} \sim 1.6 \mathrm{~V}, 0 \mathrm{~V} \sim 1.4 \mathrm{~V}$ and $0 \mathrm{~V} \sim 1.6 \mathrm{~V}$, scanning at a rate of $100 \mathrm{mV} / \mathrm{s}$ repeatedly at room temperature $\left(25^{\circ} \mathrm{C}\right)$. The polymer film was deposited on to working electrode 
with, cleaned with methylene chloride and dried. Scheme 2 shows the electrochemical polymerization process of PSWS, PSWE and PSWT.

\section{Electrochemical and Spectroelectrochemical tests}

The electrochemical properties of

Poly(2,7-Di-thiophen-2-yl-fluoren-9-one)(PSWS),

Poly(2-(2,3-Dihydro-thieno[3,4b][1,4]-dioxin-5-yl)-7-thiophen-2-yl-fluoren-9-one)(P

SWE) and Poly-(2-(4-Diphenylamino-phenyl)-7-thiophen-2-yl-fluoren-9-one)

(PSWT) film were studied by cyclic voltammetry $(\mathrm{CV})$, with a three-electrode system including 0.1 M TBAP dissolved in $\mathrm{CH}_{2} \mathrm{Cl}_{2} / \mathrm{ACN}(3 / 2, \mathrm{v} / \mathrm{v})$ as electrolyte, indium tin oxide (ITO) glass coated with the film as he working electrode, platinum wire as the counter electrode, and $\mathrm{Ag} / \mathrm{AgCl}$ as the reference electrode. The spectroelectrochemical properties of PSWS, PSWE and PSWT films were investigated via UV-vis spectroscopy in a monomer-free electrolyte system by applying different potentials.

UV-vis-NIR Absorbance Test 


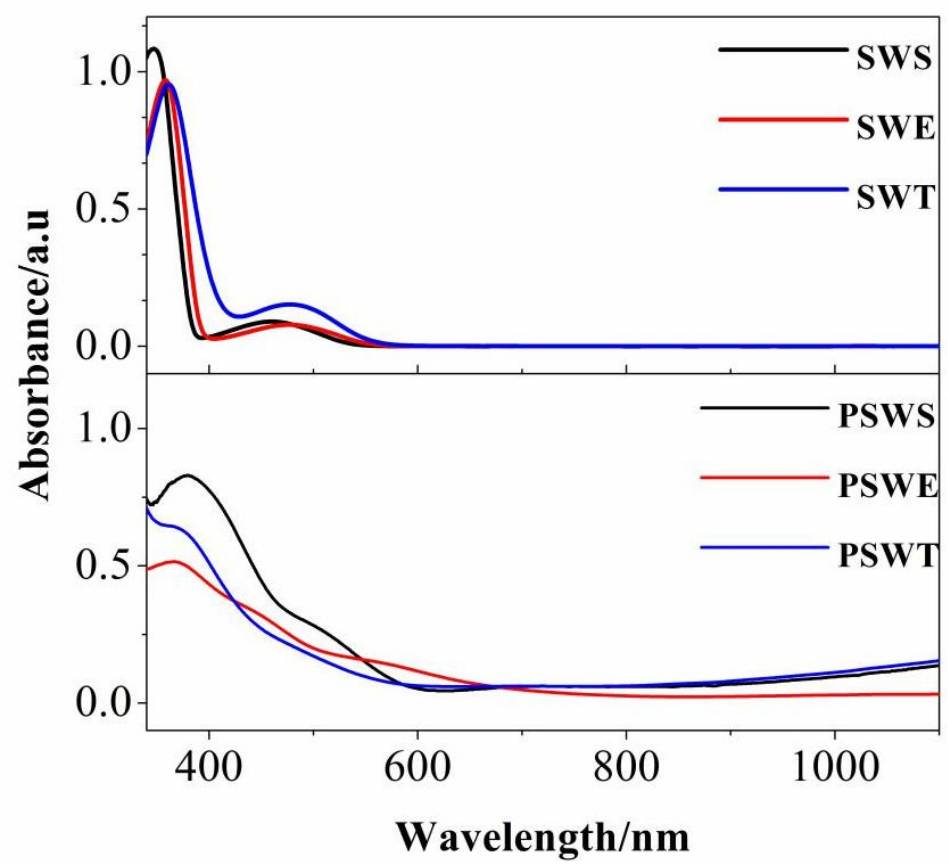

Figure S1 The UV-vis-NIR absorbance test pattern of monomers and polymers. 